\title{
GERMINAÇÃO DE SEMENTES DE Bauhinia spp.
}

\author{
José Carlos Lopes*, Luciana Gomes Barbosa**, Marilda Torres Capucho*** \\ *Eng. Agrônomo, Dr., Depto. de Fitotecnia, UFES - sementes@cca.ufes.br \\ **Eng ${ }^{\text {a }}$. Agrônoma, M.Sc., Doutoranda em Ecologia, Conservação e Manejo da Vida Silvestre, UFMG \\ ***Enga . Agrônoma, Depto. de Fitotecnia, UFES
}

Recebido para publicação: 28/11/2005 - Aceito para publicação: 15/12/2006

\begin{abstract}
Resumo
O presente trabalho teve como objetivo caracterizar e estudar o comportamento germinativo das sementes de Bauhinia variegata $\mathrm{L}$. var. candida e variegata, e Bauhinia forficata Link var. forficata. $\mathrm{O}$ delineamento foi inteiramente casualizado, com 4 repetições. Os tratamentos utilizados em Bauhinia variegata foram: água a $97^{\circ} \mathrm{C}$ até esfriar, água a $70^{\circ} \mathrm{C}$ durante 1 e 2 minutos, ácido sulfúrico durante 1, 2 e 3 minutos, escarificação mecânica e sementes intactas (controle); e em Bauhinia forficata, escarificação mecânica, imersão em ácido sulfúrico durante 5 e 10 minutos, armazenamento de sementes intactas durante seis meses, ácido sulfúrico durante 5 minutos e sementes recém-colhidas (controle). Tratamento com escarificação mecânica reduz a dormência das sementes de Bauhinia forficata e aumenta a porcentagem de germinação de Bauhinia variegata var. cândida e a velocidade de germinação das sementes Bauhinia variegata var. variegata. Tratamentos com ácido sulfúrico durante um minuto aumentam a velocidade de germinação das sementes Bauhinia variegata var. variegata e, por 10 minutos, reduzem os mecanismos de dormência das sementes de Bauhinia forficata. O armazenamento e a imersão das sementes de Bauhinia forficata Link var. forficata em ácido sulfúrico aumentam a germinação. A termoterapia a $97{ }^{\circ} \mathrm{C}$ determina a morte das sementes de Bauhinia variegata var. variegata.

Palavras-chave: Vigor; dormência; sementes armazenadas; escarificação.
\end{abstract}

\begin{abstract}
Germination of seeds of Bauhinia spp. This present research was carried out with objective of studying the influence of pregermitive treatments on the germination of seeds of Bauhinia variegata L. var. candida e variegata and Bauhinia forficata Link var. forficata. The experimental design was completely randomized blocks with four replications. The treatments were: Bauhinia variegata - hot water soak at $97{ }^{\circ} \mathrm{C}$; hot water soak $70{ }^{\circ} \mathrm{C}$ during 1 and 2 minutes sulphuric acid soak for 1,2 and 3 minutes mechanical scarification and control (intact seeds); Bauhinia forficata - mechanical scarification; sulphuric acid soak for 5 and 10 minutes, storage intact seeds for six months, storage and sulphuric acid soak for 5 minutes and control (intact seeds). The mechanical scarification of Bauhinia forficata seed reduces seed coat dormancy, increases the germination of Bauhinia variegata var., candida and the germination speed of Bauhinia variegata var. variegata. sulphuric acid soak for one minute increase the germination speed of Bauhinia variegata var. variegata seed, and for 10 minutes, decrease the dormancy coatseed of Bauhinia forficata seeds. The storage and immersion of the Bauhinia forficata Link var. forficata seed in pure sulphuric acid increse the seeds germination. The treatment of Bauhinia variegata var. variegata in hot water soak at $97{ }^{\circ} \mathrm{C}$ induces the seed deterioration.

Keywords: Vigor; dormancy; stored seeds; scarification.
\end{abstract}

\section{INTRODUÇÃO}

Atualmente, as espécies florestais, principalmente as que possuem efeitos fitoterápicos, vêm sendo amplamente estudadas visando proteger de alguma forma a biodiversidade das florestas nativas devido ao extrativismo e à comercialização irracional. 
Espécies do gênero Bauhinia, conhecidas como unha-de-vaca, são Caesalpiniaceae amplamente utilizadas na preparação de medicamentos, na indústria de celulose, caixotaria, como planta apícola, na produção de mel, na alimentação animal e na ornamentação de ruas e praças (CARVALHO, 2003). Dentre elas, as espécies variegata var. candida e var. variegata, originárias da Ásia, são as mais encontradas em ornamentação de ruas, adaptando-se aos mais variados ambientes e solos (ALZUGARAY; ALZUGARAY, 1988). A espécie forficata é nativa brasileira, encontrada principalmente em capoeiras, margens de estradas e em matas ciliares, com duas variedades: platypetala, que ocorre nos estados do Maranhão, Pará e Mato Grosso do Sul, e forficata, encontrada em matas dos estados do Ceará, Bahia, Espírito Santo, Rio de Janeiro, Minas Gerais, São Paulo e Paraná. São plantas pioneiras, de rápido crescimento e recomendadas para plantios mistos destinados a recomposição vegetal arbórea (LORENZI, 1992; PEREIRA, 1992).

As espécies florestais apresentam grande variação no poder germinativo de suas sementes devido à diversificação ecológica existente dentro de sua área de distribuição natural (AMARAL et al., 1978). No caso das leguminosas, suas sementes apresentam, em sua maioria, o fenômeno da dormência, o que é controlado geneticamente, variando entre espécies e variedades e sofrendo influência das condições ambientais durante a sua maturação e armazenamento (GUERRA et al., 1982).

A germinação se caracteriza por uma série seqüencial de eventos morfogenéticos, que resultam na transformação de um embrião em uma plântula. É um processo dinâmico envolvendo divisão e expansão celular e formação dos órgãos da planta, como folhas, caules e raízes (BERLYN, 1972). Entretanto, para que ela ocorra, é necessário o substrato, que haja disponibilidade de água em níveis ideais, de acordo com o tipo de semente, composição de gases e temperaturas adequadas, além de luz, que é exigida para certas espécies (MAYER; POLJAKOFF-MAYBER, 1989).

O presente trabalho teve como objetivo caracterizar e estudar o comportamento germinativo das sementes de Bauhinia variegata L. var. candida e variegata e de Bauhinia forficata Link var. forficata.

\section{MATERIAL E MÉTODOS}

Sementes de Bauhinia variegata L. var. candida e variegata e de Bauhinia forficata Link var. forficata foram coletadas antes da deiscência das vagens, entre setembro e outubro de 1997, em árvores matrizes existentes na região de Aracruz, Viçosa e Ibitirama, e armazenadas por 6 meses em geladeira a 3 $\pm 1{ }^{\circ} \mathrm{C}$. Sementes recém-colhidas e armazenadas foram analisadas quanto ao conteúdo de água pelo método de estufa a $105 \pm 3{ }^{\circ} \mathrm{C} / 24$ horas, com quatro repetições de 25 sementes, sendo os resultados expressos em porcentagens, com base no peso das sementes úmidas (BRASIL, 1992); quanto às características físicas, feita utilizando-se oito repetições de 20 frutos para quantificação das sementes/fruto e oito repetições de 20 sementes para essa caracterização; capacidade de embebição das sementes, estudada utilizando-se duas repetições de 25 sementes intactas e escarificadas com lixa d'água $\mathrm{n}^{\circ} 100$, imersas em água destilada a $25^{\circ} \mathrm{C}$ durante oito horas na presença de luz branca. A cada intervalo de duas horas, as sementes eram enxugadas com papel de filtro e pesadas em balanças com precisão de $0,0001 \mathrm{~g}$. Os resultados foram apresentados em porcentagem de aumento de peso, em relação ao peso da massa fresca inicial, e em porcentagem de germinação, conduzida com quatro repetições de 25 sementes para cada tratamento, distribuídas em placas de Petri com diâmetro de $11 \mathrm{~cm}$ forradas com papel-filtro, com peso específico de $80 \mathrm{~g} \mathrm{~m}^{-1}$ e porosidade de $3 \mu$, umedecidos com $15 \mathrm{~mL}$ de água destilada. As placas foram mantidas em câmara de germinação tipo BOD regulada a $30^{\circ} \mathrm{C}$, equipada com lâmpadas fluorescentes de luz branca e fria, com fotoperíodo de 8-16 horas (luz-escuro) (BRASIL, 1992). Os experimentos foram conduzidos no Laboratório de Tecnologia e Análise de Sementes no Centro de Ciências Agrárias da Universidade Federal do Espírito Santo (CCA-UFES), utilizando-se o delineamento experimental inteiramente casualizado com quatro repetições. Os tratamentos utilizados para Bauhinia variegata L. var. candida e variegata foram: termoterapia com imersão em água à temperatura de ebulição $\left(97^{\circ} \mathrm{C}\right)$ até esfriar, água a $70^{\circ} \mathrm{C}$ durante 1 e 2 minutos, imersão em ácido sulfúrico concentrado durante 1, 2 e 3 minutos, escarificação mecânica, feita com lixa d'água $n^{\circ} 100$, na região oposta ao eixo embrionário e sementes intactas como controle. As sementes de Bauhinia forficata Link var. forficata recém-colhidas foram tratadas com escarificação mecânica, imersão em ácido sulfúrico concentrado durante 5 e 10 minutos, sementes armazenadas na geladeira $\left(3 \pm 1^{\circ} \mathrm{C}\right)$ acondicionadas em embalagens de 
pano durante seis meses sem tratamento e tratadas com ácido sulfúrico concentrado por cinco minutos e sementes recém-colhidas como controle. A verificação do número de sementes germinadas foi feita diariamente durante 21 dias, sendo a germinação considerada efetiva a partir da protrusão da raiz primária com cerca de $2 \mathrm{~mm}$ para cálculo do IVG, feito de acordo com Maguirre (1962). No final do experimento, foram calculadas as porcentagens de germinação (plântulas normais), sementes deterioradas e dormentes.

A partir dos dados de germinação diária, foram calculados ainda o tempo médio de germinação: $\mathrm{t}=\Sigma$ niti/ $\Sigma$ ni, onde ni $=$ número de sementes germinadas e $\mathrm{ti}=$ tempo de incubação (dias); a velocidade média de germinação: $\mathrm{V}=1 / \mathrm{t}$, onde $\mathrm{t}=$ tempo médio de germinação; e a freqüência relativa de germinação em função do tempo de incubação: $\mathrm{fr}=\mathrm{ni} / \Sigma \mathrm{ni}$, onde $\mathrm{ni}=\mathrm{n}^{\mathrm{o}}$ de sementes germinadas por dia e $\Sigma \mathrm{ni}=$ número total de sementes germinadas (LABOURIAU; VALADARES, 1976).

Os dados obtidos foram submetidos à análise de variância, com aplicação do teste F. Para tanto, os dados que não apresentavam uma distribuição normal e homogeneidade de variância foram transformados em arco seno $\sqrt{X / 100}$. Na comparação das médias, utilizou-se o teste de Tukey a $5 \%$, sendo apresentados na tabela os dados originais.

\section{RESULTADOS E DISCUSSÃO}

Os dados referentes às características físicas das sementes estão agrupados na tabela 1.

Tabela 1. Características físicas de sementes de Bauhinia forficata e Bauhinia variegata var. candida.

Table 1. Physical characteristics of Bauhinia forficata and Bauhinia variegata var. candida seeds.

\begin{tabular}{lcc}
\hline Características & Bauhinia variegata var. candida & Bauhinia forficata \\
\hline Umidade (\%) & 16,00 & 19,00 \\
Massa de mil sementes (g) & 169,00 & 155,00 \\
Número de sementes por kg & 5.922 & 6.400 \\
Largura (mm) & $8,50 \pm 0,3$ & $7,00 \pm 0,13$ \\
Comprimento (mm) & $11,48 \pm 0,6$ & $10,00 \pm 0,5$ \\
№ médio de sementes/fruto & 15 & 5 \\
\hline
\end{tabular}

A umidade média verificada após a coleta, processamento e extração da semente de Bauhinia variegata foi de $16 \%$, e de Bauhinia forficata foi de $19 \%$. Para as sementes de Bauhinia variegata foi encontrada uma média de 15 sementes por fruto, com dimensões de 11,48x8,50 mm. A massa de mil sementes foi de $169 \mathrm{~g}$, resultando num total de 5.922 sementes por quilo. Na espécie Bauhinia forficata foi quantificada uma média de 5 sementes por fruto, com dimensões de 10,0x7,0 mm. A massa de mil sementes foi de $155 \mathrm{~g}$, dando cerca de 6.400 sementes por quilo.

A figura 1 evidencia que as espécies Bauhinia variegata var. candida e Bauhinia forficata, durante o processo de embebição, tanto para as sementes escarificadas como para as sementes nãoescarificadas, apresentaram aumento no peso de matéria fresca, indicando menores restrições à passagem de água através do tegumento e conseqüentemente menor dureza e impermeabilidade do mesmo à água. Segundo Rolston (1978), a dificuldade de entrada de água nas sementes se deve à presença de ceras e compostos graxos na superfície ou camada de células abaixo da cutícula, os macroesclerídeos. A dureza do tegumento é atribuída especialmente à camada de células em paliçada, que é constituída de paredes espessas e recobertas externamente por uma camada cuticular cerosa (POPINIGIS, 1985).

Em sementes de Bauhinia variegata var. candida (Figura 2 e Tabela 2) a escarificação mecânica aumentou significativamente a porcentagem de germinação $(98 \%)$ em relação ao controle $(70 \%)$ e aos demais tratamentos. Nos tratamentos feitos com imersão das sementes em água quente a $70{ }^{\circ} \mathrm{C}$, durante um e dois minutos, o processo germinativo apresentou-se com valor de tempo médio menor do que o controle, sem, contudo diferir estatisticamente. Mayer e Poljakoff-Mayber (1989) afirmam que a água fervente pode determinar desnaturação das proteínas do tegumento, aumentando a passagem de água e hidratação das sementes. Entretanto, no tratamento feito com imersão das sementes em água à temperatura de ebulição até esfriar, verificou-se completa inibição do processo germinativo, culminando com $100 \%$ de sementes mortas, concordando com os resultados obtidos por Lopes et al. (1998), em que 
a escarificação térmica determinou efeito letal nas sementes. Embora esse tratamento tenha determinado o amolecimento do tegumento e acelerado a absorção de água, culminou com alta taxa de sementes deterioradas. Varela et al. (1991), trabalhando com espécies amazônicas, também verificaram danos em sementes de Stryphnodendron pulcherimun, quando tratadas com água quente, à temperatura de $90{ }^{\circ} \mathrm{C}$. Verifica-se através desses resultados que a utilização de água quente afeta acentuadamente o tegumento das sementes, facilitando a absorção de água e melhorando o processo germinativo, entretanto, a elevação da temperatura da água de $70{ }^{\circ} \mathrm{C}$ para a temperatura de ebulição (cerca de $97{ }^{\circ} \mathrm{C}$ ) culminou com aumento da porcentagem de sementes mortas.

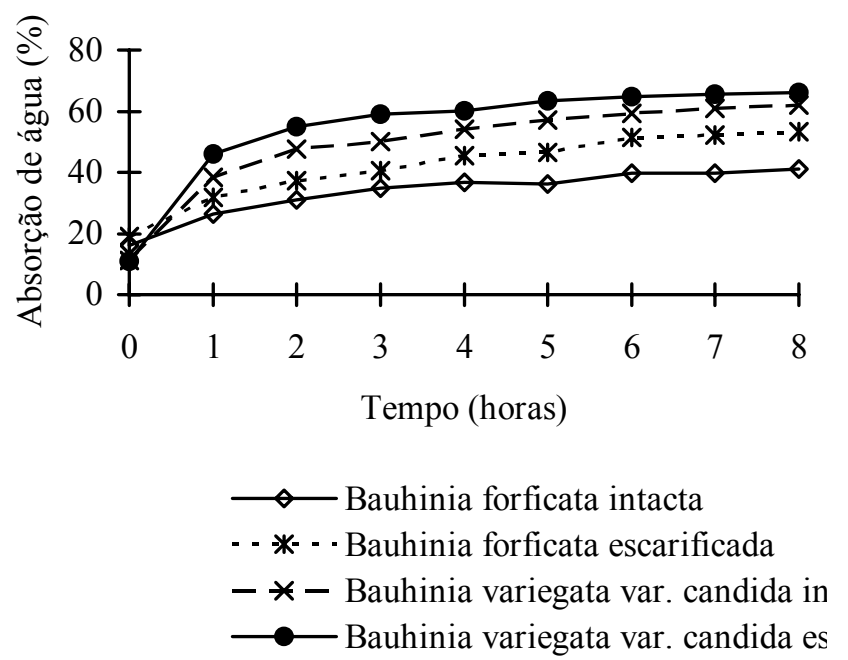

Figura 1. Curva de embebição de sementes Bauhinia forficata e Bauhinia variegata var. candida, intacta e escarificada. Laboratório de Sementes.

Figure 1. Water absorption speed of Bauhinia forficata and Bauhinia variegata var. candida of seed intact and scarified seeds.

Tabela 2. Germinação (\%), Índice de Velocidade de Germinação (IVG) e Sementes Deterioradas (\%) de Bauhinia variegata L., var. candida. Laboratório de Sementes.

Table 2. Germination (\%), germination speed (IVG) and deteriorated seeds (\%) of Bauhinia variegata L., var. candida.

\begin{tabular}{lccc}
\hline Tratamentos & $\begin{array}{c}\text { Germinação } \\
\text { (\%) }\end{array}$ & IVG & $\begin{array}{c}\text { Sementes deterioradas } \\
\text { (\%) }\end{array}$ \\
\hline $\mathrm{H}_{2} \mathrm{SO}_{4} / 1$ minuto & $38,00 \mathrm{c}$ & $1,91 \mathrm{~b}$ & 62,00 \\
$\mathrm{H}_{2} \mathrm{SO}_{4} / 2$ minutos & $23,00 \mathrm{c}$ & $1,52 \mathrm{~b}$ & 77,00 \\
$\mathrm{H}_{2} \mathrm{SO}_{4} / 3$ minutos & $35,0 \mathrm{c}$ & $1,89 \mathrm{~b}$ & 65,00 \\
Água a $97^{\circ} \mathrm{C}$ até esfriar & $0,00 \mathrm{~d}$ & $0,00 \mathrm{c}$ & 100,00 \\
Água a $70^{\circ} \mathrm{C} / 1$ minuto & $76,00 \mathrm{~b}$ & $4,80 \mathrm{a}$ & 24,00 \\
Água a $70^{\circ} \mathrm{C} / 2$ minutos & $80,00 \mathrm{~b}$ & $5,29 \mathrm{a}$ & 20,00 \\
Escarificação mecânica & $98,00 \mathrm{a}$ & $6,14 \mathrm{a}$ & 2,00 \\
Controle & $70,00 \mathrm{~b}$ & $4,47 \mathrm{a}$ & 30,00 \\
\hline $\mathrm{CV}$ & $17,2 \%$ & $10,6 \%$ & - \\
\hline
\end{tabular}

Médias seguidas de mesma letra não diferem significativamente entre si pelo teste de Tukey a $5 \%$ de probabilidade. 

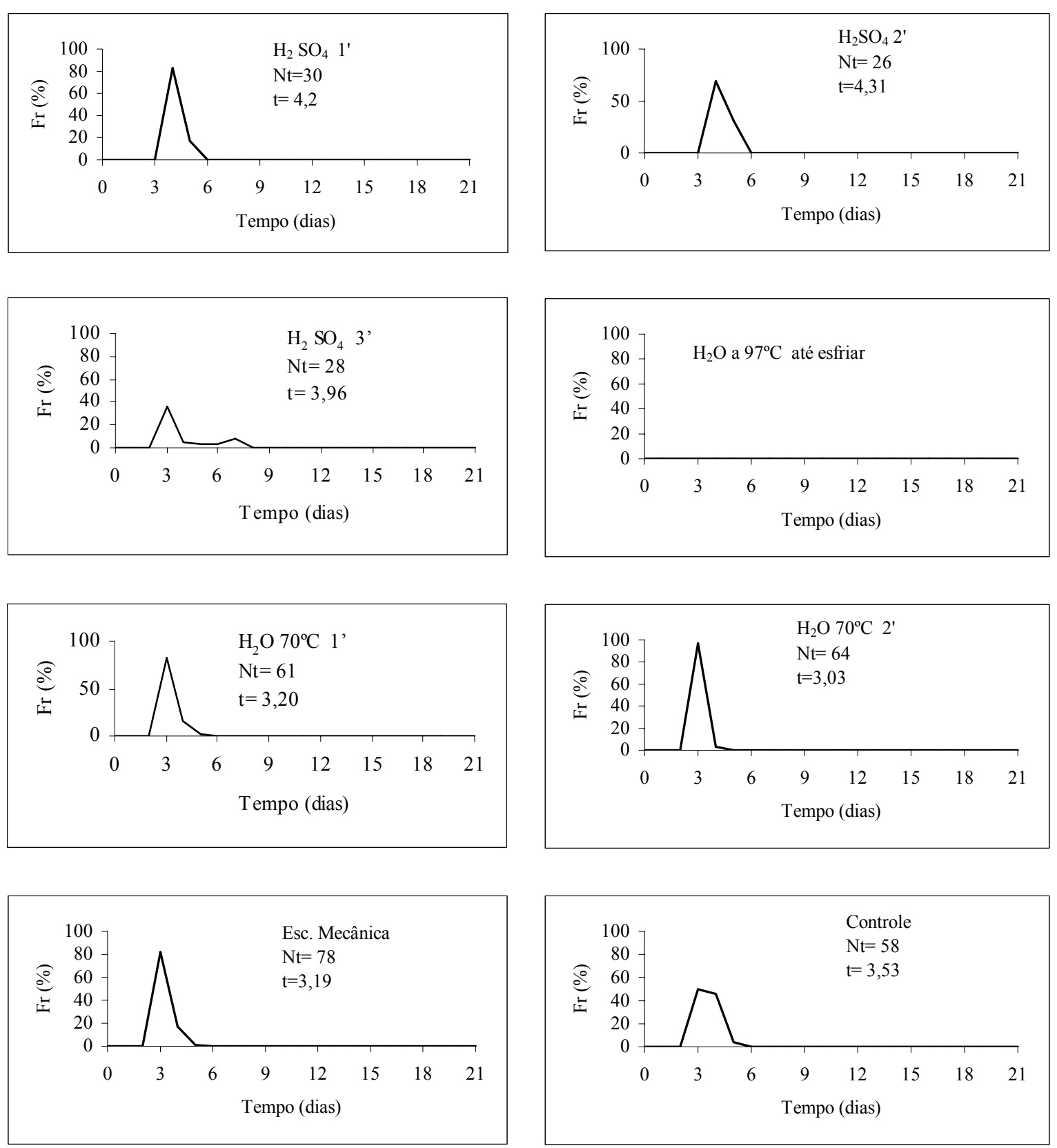

Figura 2. Freqüência relativa (Fr) da germinação de sementes de Bauhinia variegata var. candida após diferentes tratamentos pré-germinativos. $(\mathrm{Nt}=$ número total de sementes germinadas; $\mathrm{t}=$ tempo médio de germinação).

Figure 2. Germination relative frequency (Fr) of Bauhinia variegata seeds var. candida after different pay-germinatives treatments. $(\mathrm{Nt}=$ total number of germinated seeds and $\mathrm{t}=$ mean time of germination).

Em sementes de Bauhinia variegata var. variegata (Tabela 3 e Figura 3), a germinação das sementes recém-colhidas apresentou $95 \%$. Os tratamentos feitos com imersão das sementes em ácido sulfúrico concentrado durante um minuto e com escarificação mecânica mostraram resultados de germinação semelhantes ao controle, diferindo somente na velocidade de germinação, que foi 
significativamente maior. A aplicação desses tratamentos determinou valor de tempo médio de germinação significativamente menor. Quando as sementes foram tratadas com água quente, apresentaram redução na porcentagem e na velocidade de germinação, com conseqüente aumento na porcentagem de sementes mortas, quando se utilizou água na temperatura de ebulição $\left(97^{\circ} \mathrm{C}\right)$ até esfriar.

Tabela 3. Germinação (\%), Índice de Velocidade de Germinação (IVG) e Sementes Deterioradas (\%) de Bauhinia variegata $\mathrm{L}$., var. variegata.

Table 3. Germination (\%), Index of Germination speed (IVG) and Spoiled Seeds (\%) of Bauhinia variegata L., var. variegata.

\begin{tabular}{lccc}
\hline Tratamentos & $\begin{array}{c}\text { Germinação } \\
(\%)\end{array}$ & IVG & $\begin{array}{c}\text { Sementes deterioradas } \\
(\%)\end{array}$ \\
\hline $\mathrm{H}_{2} \mathrm{SO}_{4} / 1$ minuto & $91,00 \mathrm{ab}$ & $5,33 \mathrm{ab}$ & 9,00 \\
$\mathrm{H}_{2} \mathrm{SO}_{4} / 2$ minutos & $65,00 \mathrm{~d}$ & $4,00 \mathrm{bc}$ & 35,00 \\
$\mathrm{H}_{2} \mathrm{SO}_{4} / 3$ minutos & $73,00 \mathrm{bc}$ & 27,00 \\
Água a $97{ }^{\circ} \mathrm{C}$ até esfriar & $0,00 \mathrm{e}$ & $4,66 \mathrm{bc}$ & 100,00 \\
Água a $70{ }^{\circ} \mathrm{C} / 1$ minuto & $73,00 \mathrm{bc}$ & $0,00 \mathrm{~d}$ & 27,00 \\
Água a $70^{\circ} \mathrm{C} / 2$ minutos & $71,00 \mathrm{~cd}$ & $4,71 \mathrm{abc}$ & 29,00 \\
Escarificação mecânica & $91,00 \mathrm{ab}$ & $4,54 \mathrm{bc}$ & 9,00 \\
Controle & $95,00 \mathrm{a}$ & $5,86 \mathrm{a}$ & 5,00 \\
CV & $11,7 \% 0$ & $3,79 \mathrm{c}$ & - \\
\hline
\end{tabular}

Médias seguidas de mesma letra não diferem significativamente entre si pelo teste de Tukey a $5 \%$ de probabilidade.

Em sementes de Bauhinia forficata Link var. forficata (Tabela 4 e Figura 4) a utilização de tratamentos pré-germinativos evidenciaram aumento significativo no número de sementes germinadas e redução no tempo médio de germinação. A escarificação mecânica e a escarificação com ácido sulfúrico concentrado durante 5 e 10 minutos determinaram aumento significativo na porcentagem de germinação das sementes de Bauhinia forficata Link var. forficata em relação ao controle. Entretanto, maior vigor, avaliado através do índice de velocidade de germinação (Tabela 4), foi evidenciado pelas sementes armazenadas e tratadas com ácido sulfúrico durante 5 minutos, e pelas tratadas com escarificação química durante 5 e 10 minutos. Na figura 4, quando se analisa os polígonos de freqüência relativa da germinação, verificam-se dois polígonos unimodais nos tratamentos feitos com ácido sulfúrico durante 5 e 10 minutos, com deslocamento do tempo médio de germinação para a esquerda do polígono. Embora tenha sido verificado que as sementes dessa espécie apresentam embebição, concordando com Pereira (1992), segundo o qual essa espécie não apresenta impermeabilidade à água, a germinação foi significativamente maior nas sementes tratadas com escarificação mecânica e com $\mathrm{H}_{2} \mathrm{SO}_{4}$, concordando com Carvalho (2003), segundo o qual essas sementes apresentam dormência físiológica, necessitando de tratamentos especiais para aumentar a taxa de germinação. Por outro lado, a impermeabilidade do tegumento à água está associada às espécies de diversas famílias botânicas, ocorrendo com mais freqüência nas Leguminosas (CARVALHO; NAKAGAWA, 2000).

Tabela 4. Germinação (\%), índice de velocidade de germinação (IVG), sementes deterioradas e sementes dormentes de Bauhinia forficata Link var. forficata após tratamentos pré-germinativos.

Table 4. Germination (\%), index of germination speed (IVG), spoiled seeds and dormant seeds of Bauhinia forficata Link var. forficata after treatments daily pay-germinatives.

\begin{tabular}{lcccc}
\hline Tratamentos & $\begin{array}{c}\text { Germinação } \\
(\mathbf{\%})\end{array}$ & IVG & $\begin{array}{c}\text { Sementes deterioradas } \\
(\mathbf{\%})\end{array}$ & $\begin{array}{c}\text { Sementes dormentes } \\
(\mathbf{\%})\end{array}$ \\
\hline $\mathrm{H}_{2} \mathrm{SO}_{4} 5$ & $83,00 \mathrm{~b}$ & $5,29 \mathrm{ab}$ & 17,00 & 0,00 \\
$\mathrm{H}_{2} \mathrm{SO}_{4} 10$ & $84,00 \mathrm{ab}$ & $3,96 \mathrm{~b}$ & 16,00 & 0,00 \\
Escarificação mecânica & $74,00 \mathrm{~b}$ & $2,34 \mathrm{c}$ & 26,00 & 0,00 \\
Armazenada 6 meses & $75,00 \mathrm{~b}$ & $0,78 \mathrm{e}$ & 12,00 & 13,00 \\
Armazenada e $\mathrm{H}_{2} \mathrm{SO}_{4} 5$ & $92,00 \mathrm{a}$ & $5,94 \mathrm{a}$ & 8,00 & 0,00 \\
Controle & $44,00 \mathrm{c}$ & $1,36 \mathrm{de}$ & 21,00 & 35,00 \\
$\mathrm{CV}$ & $11,9 \%$ & $8,5 \%$ & - & \\
\hline
\end{tabular}

Médias seguidas de mesma letra não diferem significativamente entre si pelo teste de Tukey a $5 \%$ de probabilidade. 

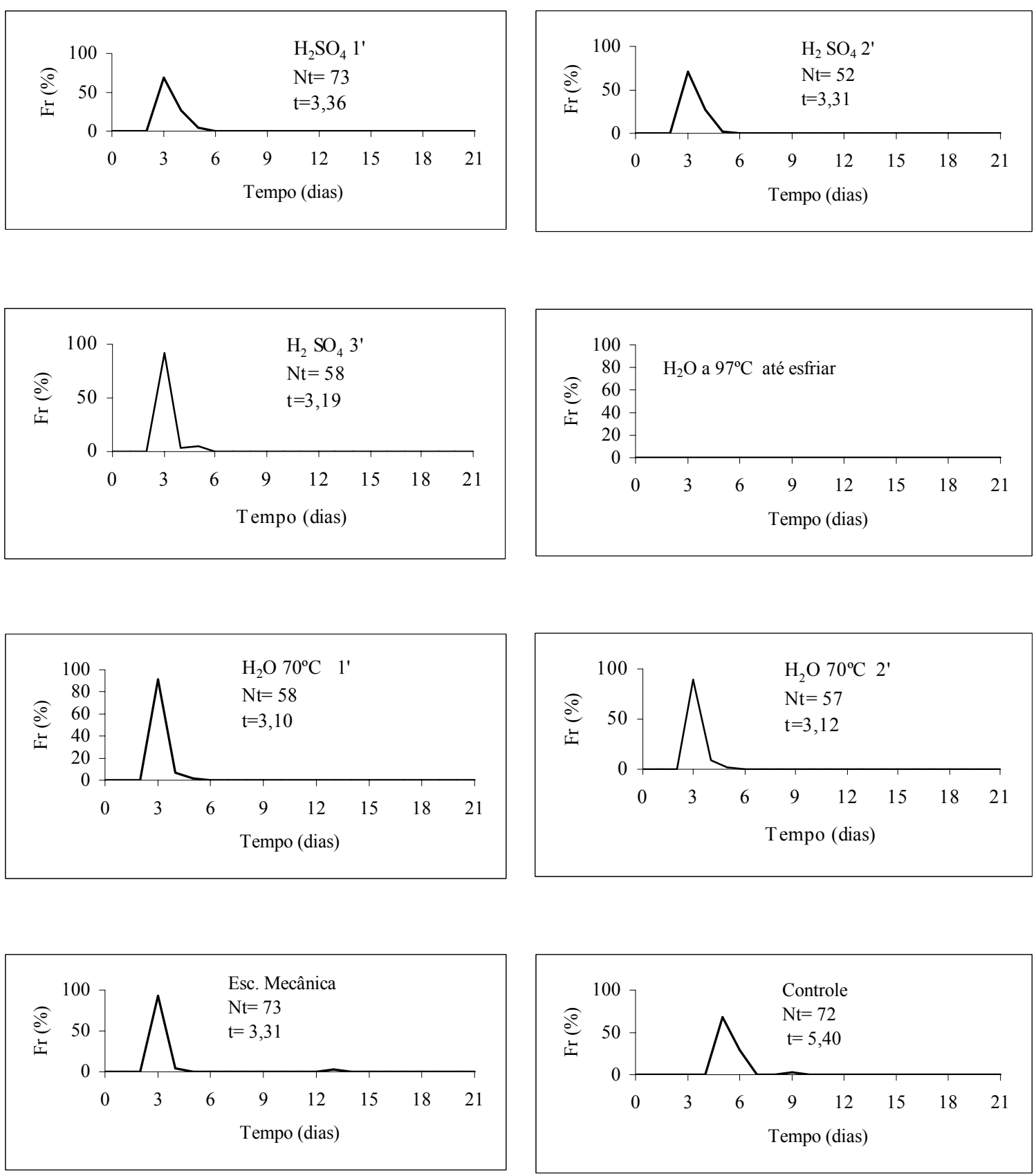

Figura 3. Freqüência relativa (Fr) da germinação de sementes de Bauhinia variegata var. variegata após diferentes tratamentos pré-germinativos. $(\mathrm{Nt}=$ número total de sementes germinadas; $\mathrm{t}=$ tempo médio de germinação).

Figure 3. Relative frequency (Fr) of germination of seeds of Bauhinia variegata var. variegata after different treatments daily pay-germinatives. $(\mathrm{Nt}=$ total number of germinated seeds and $\mathrm{t}=$ average time of germination).

O armazenamento das sementes de Bauhinia forficata Link var. forficata por um período de 6 meses (Tabela 4) determinou aumento significativo na porcentagem de germinação, tanto nas sementes tratadas $(92 \%)$ como nas sementes não tratadas $(75 \%)$, em relação ao controle (44 \%), cujo polígono de 
freqüência (Figura 4) evidenciou polimodalidade após o período de armazenamento. Entretanto, o tempo de armazenamento evidenciou redução no vigor das sementes, cujo índice de velocidade de germinação foi significativamente menor $(0,78)$ do que nas sementes recém-colhidas (controle $=1,36$ ). De acordo com Bewley e Black (1994), a dormência pode atrasar o início da germinação das sementes, e em todos os tratamentos feitos para acelerar e uniformizar a germinação dessas sementes, verificou-se redução no tempo médio de germinação em relação ao controle. No caso do armazenamento (Figura 4), o tempo médio de germinação foi longo, apresentando redução somente quando as sementes foram tratadas com ácido sulfúrico durante 5 minutos, acarretando aumento na porcentagem de germinação das sementes. Apesar da germinação após esse período de armazenamento ter sido alta em relação ao controle, o índice de velocidade de germinação foi menor, com conseqüente perda da qualidade fisiológica da semente, $o$ que acarretará maior deterioração das sementes, de acordo com a adversidade das condições de armazenamento destas (ROBERTS, 1986).
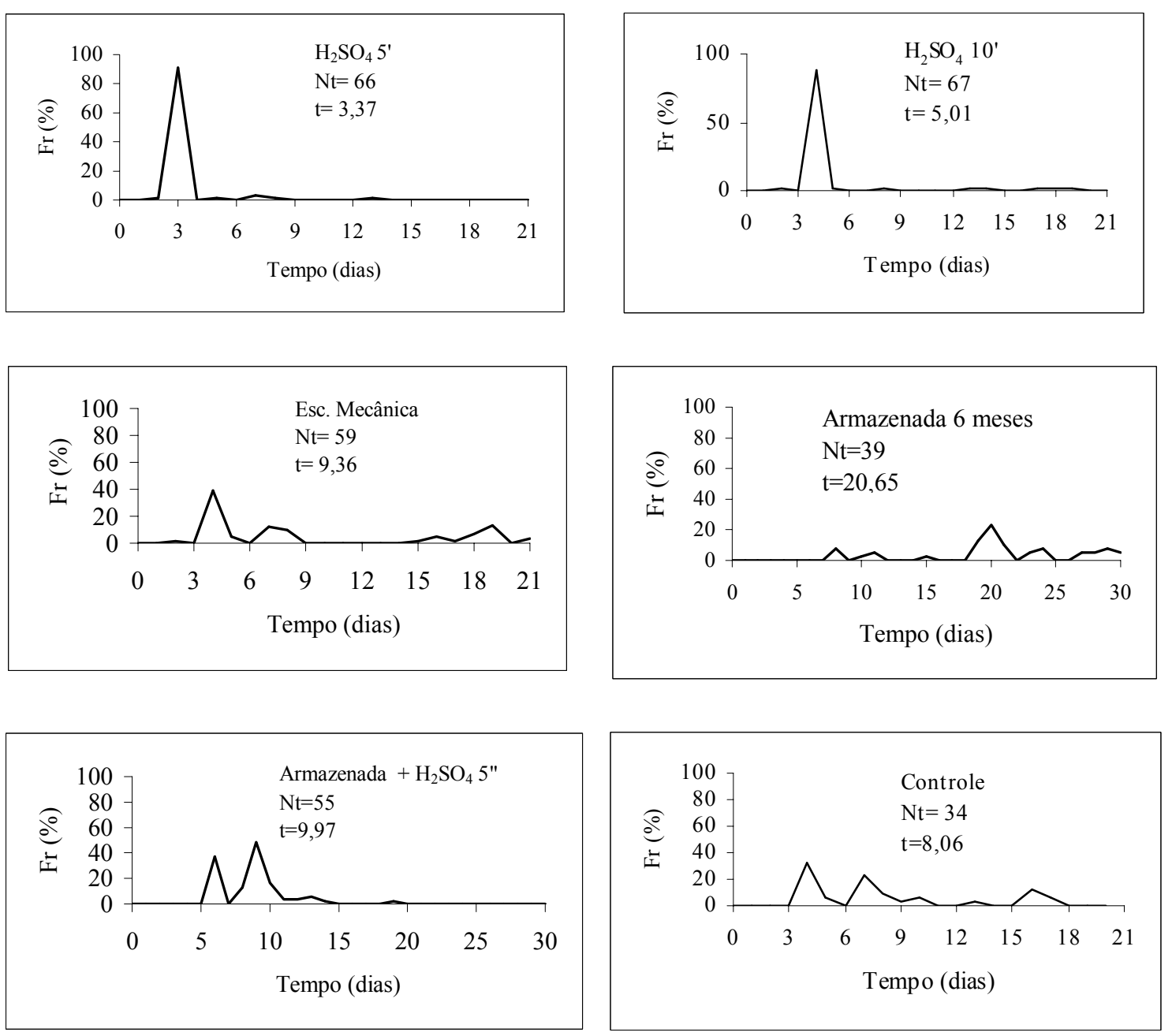

Figura 4. Freqüência relativa (Fr) da germinação de sementes de Bauhinia forficata Link var. forficata após diferentes tratamentos pré-germinativos. $(\mathrm{Nt}=$ número total de sementes germinadas; $\mathrm{t}=$ tempo médio de germinação).

Figure 4. Relative frequency (Fr) of germination of seeds of Bauhinia forficata Link var. forficata after different treatments daily pay-germinatives. $(\mathrm{NT}=$ total number of seeds germinated $\mathrm{t}=$ average time of germination). 


\section{CONCLUSÕES}

Nas condições em que foram desenvolvidos os trabalhos, conclui-se que:

- Tratamentos pré-germinativos, como escarificação mecânica e imersão em ácido sulfúrico concentrado durante 10 minutos, reduzem os mecanismos de dormência das sementes de Bauhinia forficata Link var. forficata.

- Tratamentos com escarificação mecânica e $\mathrm{H} 2 \mathrm{SO} 4$ por um minuto aumentam a velocidade de germinação das sementes Bauhinia variegata var. variegata.

- Tratamento com água a $97^{\circ} \mathrm{C}$ até esfriar determina a morte das sementes de Bauhinia variegata var. variegata.

- O armazenamento das sementes de Bauhinia forficata Link var. forficata, sob temperatura de $3 \pm 1{ }^{\circ} \mathrm{C}$, durante seis meses, aumenta a germinação e reduz o vigor.

- Tratamento com $\mathrm{H}_{2} \mathrm{SO}_{4}$ por tempo superior a um minuto reduz a germinação de sementes de Bauhinia variegata var. variegata.

- Escarificação mecânica aumenta a germinação de Bauhinia variegata var. candida.

- No caso de Bauhinia variegata var. variegata, à exceção da escarificação mecânica e com $\mathrm{H}_{2} \mathrm{SO} 4$ por um minuto, todos tratamentos utilizados evidenciam redução na germinação das sementes, embora aumentem a velocidade de germinação.

\section{AGRADECIMENTOS}

Os autores agradecem ao Conselho Nacional de Pesquisa e Desenvolvimento (pelos auxílios com a concessão de bolsa de iniciação científica ao segundo autor e bolsa de apoio técnico à pesquisa ao terceiro autor), ao laboratorista José Maria Barbosa pelo auxílio técnico e ao Eng ${ }^{\mathrm{o}}$ Florestal Renato Moraes de Jesus pela cessão de sementes.

\section{REFERÊNCIAS}

ALZUGARAY, D.; ALZUGARAY, C.(ed.). Enciclopédia de plantas brasileiras: a mais bela flora tropical do mundo. São Paulo: Três, 1988, v. 3.

AMARAL, D. M. I.; GALLARDO, V. R. B.; SALTZ, N. A.; JAMARDO, A. Metodização e tratamento pré-germinativo de sementes florestais. Roessleria, Porto Alegre, v. 2, n. 1, p. 41-56, 1978.

BERLYN, G. P. Seed germination and morphogenesis. In: KOZLOWSKI, T. T.(Ed.). Seed biology. New York: Academic, 1972. v. 1.

BEWLEY, J. D.; BLACK, M. Seeds: physiology of development and germination. 2. ed. New York: Plenum, 1994. $445 \mathrm{p}$.

BRASIL. Ministério da Agricultura e Reforma Agrária. Regras para análise de sementes. Brasília, DF: 1992. $365 \mathrm{p}$.

CARVALHO, N. M.; NAKAGAWA, J. Sementes: ciência tecnologia e produção. 3. ed. Campinas: Fundação Cargill, 2000. 588 p.

CARVALHO, P. E. R. Espécies arbóreas brasileiras. Brasília, DF: Embrapa Informação Tecnológica, 2003. $1039 \mathrm{p}$.

GUERRA, M. P.; NODARI, R. O.; REIS, A.; GRANDO, J. L. Comportamento da canafístula (Peltophorum dubium (Sprengel) Taubert) em viveiro, submetida a diferentes métodos de quebra de dormência e semeadura. Boletim de Pesquisa Florestal, Curitiba, n. 5, p. 1-18, 1982.

LABORIAU, L. G.; VALADARES, M. E. B. On the germination of seeds Calotropis procera (Ait) Ait.f. Anais da Academia Brasileira de Ciências, Rio de Janeiro, v. 48, n. 2, p. 263-284, 1976. 
LOPES, J. C.; CAPUCHO, M. T.; KROHLING, B.; ZANOTTI, P. Germinação de sementes de espécies florestais de Caesalpinea ferrea Mart. ex Tul. var. leiostachya Benth., Cassia grandis L. e Samanea saman Merrill, após tratamentos para superar a dormência. Revista Brasileira de Sementes, Brasília, DF, v. 20, n. 1, p. 80-86, 1998.

LORENZI, H. Árvores Brasileiras: manual de identificação e cultivo de plantas arbóreas nativas do Brasil. Nova Odessa: Plantarum, 1992. v. 1, p. 165-166.

MAGUIRRE, J. D. Speed of germination-aid in selection and evolution for seeding emergence and vigor. Crop Science, Madison, v. 2, n. 2, p. 176-177, 1962.

MAYER, A. M.; POLJAKOFF-MAYBER, A. The germination of seeds. 4. ed. Oxford: Pergamon, 1989. $270 \mathrm{p}$.

PEREIRA, T. S. Germinação de sementes de Bauhinia forficata LinK. (Leguminosae e Caesalpinoideae). Revista Brasileira de Sementes, Brasília, DF, v. 14, n. 1, 1992.

POPINIGIS, F. Fisiologia da semente. Brasília, DF: AGIPLAN, 1985. 289 p.

ROBERTS, E. H. Quantifying seed deterioration. In: McDONALD, M. B.; NELSON, C. J. (Ed.). Physiology of seed deterioration. Madison: Crop Science Society of America, 1986. p. 101-123. (Special Publication, n. 11)

ROLSTON, M. P. Water impermeable seed dormancy. The Botanical Review, New York, v. 44, n. 3, p. 365-396, 1978.

VARELA, V. P.; BROCKI, E.; SÁ, S. T. V. Tratamentos pré-germinativos de espécies da Amazônia IV. Faveira cumazê - Stryphnodendron pulcherimum (Willd.) Hochr - Leguminosae. Revista Brasileira de Sementes, Brasília, DF, v. 13, n. 2, p. 87-89, 1991. 